\title{
Personal and Perceived Peer Use of and Attitudes Toward Alcohol Among University and College Students in Seven EU Countries: Project SNIPE
}

\author{
JOHN McALANEY, PH.D., ${ }^{a, b}, *$ STEFANIE M. HELMER, M.SC., ${ }^{c}$ CHRISTIANE STOCK, PH.D., ${ }^{d}$ BART VRIESACKER,,$f$ \\ GUIDO VAN HAL, PH.D., ${ }^{e}$ ROBERT C. DEMPSEY, PH.D., ${ }^{b}$ YILDIZ AKVARDAR, PH.D., M.D., ${ }^{g}$ FERDINAND SALONNA, PH.D., ${ }^{h, i}$ \\ ONDREJ KALINA, PH.D., ${ }^{h, i}$ FRANCISCO GUILLEN-GRIMA, M.B.A., M.P.H., M.SC., PH.D., M.D., ${ }^{j, k}$ BRIDGETTE M. BEWICK, PH.D., ${ }^{l}$ \\ \& RAFAEL MIKOLAJCZYK, M.D., M.S.C. ${ }^{m}$
}

a Department of Psychology, Bournemouth University, Bournemouth, United Kingdom

${ }^{b}$ Division of Psychology, University of Bradford, Bradford, United Kingdom

${ }^{c}$ Leibniz Institute for Prevention Research and Epidemiology (BIPS), Bremen, Germany

${ }^{d}$ Unit for Health Promotion Research, University of Southern Denmark, Esbjerg, Denmark

'Medical Sociology and Health Policy, University of Antwerp, Antwerp, Belgium

${ }^{f}$ Research \& Development, Occupational Health Services Mensura, Antwerp, Belgium

${ }^{g}$ Department of Psychiatry, Marmara University School of Medicine, Istanbul, Turkey

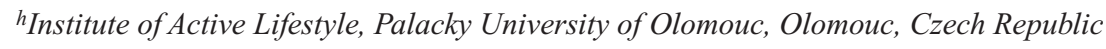

${ }^{i}$ Department of Educational Psychology \& Psychology of Health, PJ Safarik University in Košice, Košice, Slovak Republic

${ }^{j}$ Department of Health Sciences, Public University of Navarra, Navarra, Spain

kIDISNA, Navarra's Health Research Institute, Pamplona, Spain

${ }^{l}$ School of Medicine, Leeds Institute of Health Sciences, Academic Unit of Psychiatry and Behavioural Sciences, University of Leeds, Leeds, United Kingdom

${ }^{m}$ Department of Epidemiology, Helmholtz Centre for Infection Research, Braunschweig, Germany

\begin{abstract}
Objective: The objective of this study was to explore perceptions of peer substance use and related attitudes among European students. Challenging perceptions about peer substance use has become the basis of a form of prevention and intervention known as the social norms approach, which can be delivered using personalized online feedback. This article reports baseline alcohol use and attitudes data for university students across Europe collected as part of the Social Norms Intervention for the prevention of Polydrug usE project (Project SNIPE). Method: Students from universities in Belgium, Denmark, Germany, the Slovak Republic, Spain, Turkey, and the United Kingdom were recruited to take part in an online survey by the use of email invitations, social media, classroom announcements, flyers, and stalls in social areas, such as in cafeterias and bars on campus. A total of 4,482 students agreed to
\end{abstract}

participate. Results: Overall, respondents reported both perceived alcohol use and perceived acceptance of alcohol use among their peers that were higher than their own use or acceptance. Perceived peers' behaviors and attitudes were found to be predictive of personal behaviors and attitudes, with some variation across countries and by sex. Conclusions: The results suggest that students at the participating institutions across selected European countries exhibit overall similar patterns of perceptions as have been found on American college campuses. In conjunction with the finding that the perceived norm is predictive of personal behavior and attitudes, this research provides support to the view that the social norms approach may be a viable method to reduce alcohol consumption among students at European universities. (J. Stud. Alcohol Drugs, 76, 430-438, 2015)
$\mathrm{T}$ HE USE OF LICIT AND ILLICIT DRUGS is a public health issue across Europe, with $4 \%$ of all deaths in persons ages 15-39 years in the European Union being related to drug use, as reported by the European Monitoring Centre for Drugs and Drug Addiction (2011). Heavy alcohol use in young adults may result in cognitive and neurological impairments (Hartley et al., 2004; Monti et al.,

Received: March 26, 2014. Revision: December 11, 2014.

The Social Norms for the prevention of Polydrug usE (SNIPE) project was funded by the European Commission (LS/2009-2010/DPIP/AG).

*Correspondence may be sent to John McAlaney at the Department of Psychology, Faculty of Science and Technology, Bournemouth University, Bournemouth, Dorset, BH4 9HW, United Kingdom, or via email at: jmcalaney@bournemouth.ac.uk
2005), although these effects may not become permanent if the individual can be encouraged to avoid further episodes of heavy consumption (Mota et al., 2013). Additional consequences of heavy alcohol use in student populations include poor academic performance and antisocial and risky behaviors such as unsafe sexual practices as well as physical and psychological harm (Bergen et al., 2005; Boot et al., 2012; Ham \& Hope, 2003). Increased substance use is associated with entry into university or college and the first year of study (Akmatov et al., 2011; Schulenberg \& Maggs, 2002), further underlining the importance of addressing problematic use in student populations.

Within the European Union population, university and college students demonstrate hazardous rates of substance use (Akmatov et al., 2011; Karam et al., 2007; McAlaney 
et al., 2012; Stock et al., 2009). Research on European students is limited in comparison to the work that has been done on substance use among students in the American college system (Wicki et al., 2010). Caution must be taken when applying research from the United States to European universities because of the differences in culture and legislation that relate to alcohol and other substance use. Work that has been conducted to date has identified gender, ethnicity, whether the student lives with peers or in the parental home, and the substance use behaviors of peers or significant others as predictors of substance use in student populations (Boot et al., 2010; Dowdall \& Wechsler, 2002; O’Malley \& Johnston, 2002; Weitzman et al., 2005).

Research originating from the United States (Perkins, 2003), and replicated in some European studies (Lintonen \& Konu, 2004; McAlaney et al., 2011; Page et al., 2008), suggests that individuals often appear to overestimate the frequency and amount of substance use of their peers. This is referred to in the literature as an overestimation or misperception of the descriptive norm and has been identified by surveying students on their own behavior or attitude and then asking them to indicate what they think the norm is for the majority of their peers at their institution. Students also appear to misperceive the injunctive norm, which refers to how socially acceptable a behavior such as substance use is perceived to be (Borsari \& Carey, 2003). These perceptions are a form of social influence on the individual and may cause individuals to increase their own consumption in an attempt to match their estimation of their peer norm (Borsari \& Carey, 2003). Such influence may be especially powerful in the context of a university or college campus, where individuals are in close social contact with their peers (Borsari \& Carey, 2001). It has been noted that students consume alcohol primarily during social gatherings (Wicki et al., 2010). This may further heighten the importance of social influence on this behavior in student populations.

These research findings have given rise to a form of prevention and intervention known as the social norms approach. This approach originated in the American college system (Perkins, 2003) and has since been implemented at a number of college sites in the United States (McAlaney et al., 2011). The approach is based on challenging the apparent misperceptions about peer substance use and attitudes that students hold. This is achieved through mass media campaigns, social marketing strategies, and online personalized feedback approaches. These interventions aim to highlight the reported norm, provided that this is healthier and safer than the perceived norm. If, for instance, it were found that students within a population on average consumed three alcoholic drinks when partying but perceived typical students to have six alcoholic drinks when they partied, then a social norms campaign may promote and disseminate a message of, "The majority of students at [university name] have no more than three alcoholic drinks when they party."

The approach is based on the premise that challenging the perceptions of the target population will lessen the social influence to adhere to what is a misperceived norm and in turn will reduce alcohol use and positive attitudes toward alcohol use (Perkins, 2003). There is evidence supporting the efficacy of the approach in the form of a Cochrane systematic review of social norms campaigns delivered on college campuses (Moreira et al., 2009).

In recent years, Internet-based technologies have been used to deliver immediate, personalized social norms feedback (McAlaney et al., 2011). By delivering personalized and more salient feedback to the individual, it is expected that such social norms feedback becomes more influential, as predicted by social comparison theory (Festinger, 1954). Preliminary studies conducted in several countries demonstrate the potential of delivering social norms feedback via the Internet in reducing substance use in young adults (Bendtsen et al., 2006; Bewick et al., 2013). However, there remains a lack of research on the efficacy of this web-based approach to using social norms feedback and how it can be applied within a European context.

The current article reports the baseline results from a feasibility trial of an online personalized social norms feedback system, Social Norms Intervention for the Prevention of Polydrug usE (SNIPE), funded by the European Commission (LS/2009-2010/DPIP/AG). The project consisted of the development of a personalized feedback website for students attending universities in Belgium, Denmark, Germany, the Slovak Republic, Spain, Turkey, and the United Kingdom. This website was used to survey students on their substance use behaviors, attitudes, and perceptions. The results, in turn, were used as the basis for the creation of personalized social norms feedback.

The primary aim of this baseline analysis was to establish whether discrepancies between the students' reported own behavior and attitudes and perceived descriptive and injunctive norms (self-other discrepancies), similar to those found in previous studies on American college campuses, are also evident in European student populations. This could indicate the presence of the misperceptions, which are a prerequisite to implementing the social norms approach. Therefore, it is important to investigate whether students in Europe are subject to self-other discrepancies in order to determine whether the social norms approach may be a viable method for behavior change in that population.

The secondary aim was to determine how predictive these perceptions are of individual behavior. For individuals to respond to the social norms approach, it is necessary for their own behavior and attitudes to be influenced by the perceived norms they hold about their peer group. Although the perceived norm has been found to be a strong 
TABLE 1. Sample characteristics ( $n$ indicates number of participants who have given information on sex)

\begin{tabular}{|c|c|c|c|c|c|c|c|}
\hline Variable & $\begin{array}{l}\text { Slovak Republic } \\
\quad(n=1,931)\end{array}$ & $\begin{array}{l}\text { Denmark } \\
(n=461)\end{array}$ & $\begin{array}{l}\text { Germany } \\
(n=503)\end{array}$ & $\begin{array}{c}\text { Belgium } \\
(n=424)\end{array}$ & $\begin{array}{c}\text { Spain } \\
(n=184)\end{array}$ & $\begin{array}{l}\text { Turkey } \\
(n=855)\end{array}$ & $\begin{array}{l}\text { United Kingdom } \\
\qquad(n=107)\end{array}$ \\
\hline $\begin{array}{l}\text { Participant numbers from } \\
\text { individual institutions }\end{array}$ & $\begin{array}{l}n_{1}=361, n_{2}=756 \\
n_{3}=612, n_{4}=202\end{array}$ & $\begin{array}{l}n_{1}=271 \\
n_{2}=190\end{array}$ & $\begin{array}{c}n_{1}=317, \\
n_{2}=81 \\
n_{3}=105\end{array}$ & $\begin{array}{l}n_{1}=248 \\
n_{2}=176\end{array}$ & $\begin{array}{l}n_{1}=61 \\
n_{2}=123\end{array}$ & $\begin{array}{l}n_{1}=423, n_{2}=71, \\
n_{3}=144, n_{4}=71, \\
n_{5}=130, n_{6}=16\end{array}$ & $\begin{array}{l}n_{1}=96 \\
n_{2}=11\end{array}$ \\
\hline \multicolumn{8}{|l|}{ Sex, \% } \\
\hline Female & 79 & 78 & 59 & 79 & 72 & 53 & 69 \\
\hline Male & 21 & 22 & 41 & 21 & 28 & 47 & 31 \\
\hline \multicolumn{8}{|l|}{ Age, $\%$} \\
\hline$<20$ & 31 & 12 & 11 & 53 & 39 & 41 & 39 \\
\hline $21-25$ & 67 & 60 & 57 & 39 & 42 & 54 & 30 \\
\hline $26-30$ & 2 & 17 & 24 & 5 & 9 & 4 & 12 \\
\hline$\geq 31$ years & 1 & 11 & 8 & 4 & 10 & 1 & 19 \\
\hline Foreign student, \% & 1 & 12 & 7 & 8 & 9 & 4 & 34 \\
\hline $\begin{array}{l}\text { Residence (\% living } \\
\text { with other students) }\end{array}$ & 52 & 12 & 36 & 22 & 22 & 26 & 51 \\
\hline \multicolumn{8}{|l|}{ Religion, \% } \\
\hline Christian & 81 & 56 & 48 & 59 & 53 & 1 & 30 \\
\hline Muslim & 0 & 2 & 2 & 3 & 1 & 85 & 25 \\
\hline Jewish & 0 & 0 & 0 & 1 & 0 & 0 & 0 \\
\hline Hindu & 0 & 0 & 0 & 0 & 1 & 0 & 1 \\
\hline Buddhist & 1 & 1 & 2 & 2 & 1 & 0 & 3 \\
\hline Other & 3 & 6 & 4 & 3 & 3 & 4 & 9 \\
\hline No religious beliefs & 15 & 35 & 44 & 33 & 42 & 10 & 32 \\
\hline \multicolumn{8}{|l|}{ Importance of religion, $\%$} \\
\hline Not at all important & 17 & 48 & 43 & 51 & 50 & 13 & 37 \\
\hline Somewhat important & 21 & 39 & 39 & 39 & 30 & 17 & 24 \\
\hline Important & 35 & 10 & 11 & 7 & 13 & 35 & 12 \\
\hline Very important & 28 & 3 & 6 & 3 & 8 & 35 & 26 \\
\hline
\end{tabular}

predictor of personal behavior in American college students (Perkins et al., 2005), it cannot be assumed that the same type of predictive relationship is evident in European student populations because of the previously noted differences in culture between the United States and Europe.

\section{Method}

The data collection in the study is outlined in detail in a protocol article (Pischke et al., 2012). In total, 21 sites from 7 countries participated, but the distribution of sites was not equal, with 4 countries having only 2 sites each. Institutional ethical approval was awarded at all participating institutions before data collection.

\section{Participants}

All registered students at each of the participating institutions in the SNIPE project were able to take part in the survey. The final sample included 4,482 participants. Demographic information on the sample is given in Table 1. Participant numbers from universities in the United Kingdom and Spain were lower compared with those in the other countries. This was because of barriers to participant recruitment-namely, changes in university regulations that prevented the use of the student email system to invite students to take part in the project.

\section{Design}

The survey was conducted cross-sectionally at each of the institutions during the autumn semester of 2011. Participants were invited using a range of techniques including email, social media, classroom announcements, announcements on virtual learning environments, printed flyers, and stalls in social areas, such as in cafeterias and bars on campus, to register onto the survey website with their email address and were provided with a password. An anonymous user ID was assigned to each participant; this allowed students to be tracked in the follow-up survey, which was conducted as part of the wider SNIPE project. The email addresses of the participants were not visible to the project researchers, and no other personally identifying information was collected.

\section{Materials}

Because a social norms survey is, by necessity, based on a pre-defined population and setting, it was not possible to use an existing survey that had been utilized in previous research. Instead, a survey was constructed for use with the specific target population of the project. However, this was consistent with the approach taken in previous social norms research, with participants asked to report both their personal alcohol use behavior and attitudes and perceived alcohol use behavior and attitudes of their same-sex peers at their institution. 


\section{Procedure}

In the survey, respondents were asked to report their personal substance use behaviors and attitudes toward substance use and the perceived behaviors (descriptive norms) and attitudes (injunctive norms) of their peers. These latter items were phrased in terms of at least $51 \%$ of same-sex students. For example, "How often in the last two months do you think most (at least 51\%) of the [participant sex] students at [University name] will have used the following?" The survey items on alcohol use queried personal and perceived peer frequency of alcohol consumption and frequency of drinking alcohol to drunkenness, both measured on a range of response options from never in my life to every day or nearly every day in the last two months. The number of alcoholic drinks consumed on a day that alcohol is consumed and the maximum number of alcoholic drinks consumed in a single session in the last 2 months were directly recorded as numbers. Participants were provided with a definition of an alcoholic drink as half a pint of lager or beer, a shot of vodka, a small glass of wine, a shot of raki, or a small bottle of a ready-to-drink beverage. In addition, there were items on personal and perceived peer attitudes to alcohol use and to drunkenness. These used the response options of never ok to use, ok to use occasionally if it doesn't interfere with study or work, ok to use frequently if it doesn't interfere with study or work, ok to use occasionally even if it does interfere with study or work, and ok to use frequently if that is what the person wants to do.

Participants were asked to indicate their religious beliefs from the following categories: Buddhist, Christian, Hindu, Jewish, Muslim, other, no religious beliefs. They were then asked to state how important religion is to their life using the response options of not at all important, somewhat important, important, and very important. Sex was recorded with the use of a male or female response option, whereas age was recorded as a continuous variable in years. Residence type was recorded in terms of whether the student lives in university or private accommodation and whether he or she lives with other students. Further information on the development and content of the survey is available in the protocol article of the project (Pischke et al., 2012).

\section{Statistical analysis}

First, sociodemographic characteristics of the samples were described by country. We estimated the proportion of respondents who rated the behavior of the majority of their peers as more risky (e.g., more frequent consumption, more frequent drunkenness) or their attitudes as more permissible than those of the respondent himself or herself by country and sex. To indicate precision for this estimate, we added exact binomial 95\% confidence intervals. To assess variation within and between countries, a three-level binary logistic regression adjusting for sex and study year and predicting the proportion of respondents reporting peers' behavior/attitudes as more risky/permissible was used. The existence of heterogeneity was judged based on the test if the estimate of variance at a given level was different from zero. Given the unequal distribution of sites across the countries, this part is reported only as a sensitivity analysis.

Second, a binary logistic regression was used to determine the association between perceived behaviors and attitudes and personal behaviors and attitudes, with the outcome variables in the analysis dichotomized as shown in the following section. After initial analyses with a threelevel random-effects model with estimates of variance at institution level not different from zero, only countries were considered as hierarchy level in further steps. Four separate analyses were conducted for descriptive norm measures, all based on a period of the previous 2 months. These measures were frequency of alcohol use, frequency of drunkenness, average number of alcoholic drinks in a day, and maximum number of alcoholic drinks in a session. Two injunctive norm outcome measures were also analyzed, which were acceptability of alcohol use and acceptability of drunkenness.

The corresponding perceived behavior/attitudes of peers were used as independent variables in the analysis. Sex, year of the study, age, and living situation (with other students or not) were included for adjustment in the regression models, in light of previous research that has demonstrated that these may be important predictors of substance use behaviors and attitudes in student populations (Wicki et al., 2010). Whether the strength of the association between peers' and corresponding students' own behavior/attitudes differed across countries and by sex was studied by means of interaction. Initially, a two-way interaction was introduced in the models. When this interaction was significant $(p<.05)$, sex-specific estimates for effects within each country were presented; if this interaction was not significant, single estimates for both sexes were presented. In either case, an averaged effect for all countries and country-specific effects were reported, together with a significance test assessing variation across country effects.

The analysis was conducted using SPSS (Version 19) for descriptive purposes and PROC GLIMMIX in SAS (SAS Institute Inc., Cary, NC) for random effects logistic regression.

\section{Results}

The sample characteristics in terms of sex, age, residence, and foreign student status and religious beliefs are presented in Table 1. In two of the sites (the Slovak Republic and Turkey), the majority of students reported that their religion was important or very important for them. In these two countries, more than $80 \%$ of the students were either Christian (the Slovak Republic) or Muslim (Turkey). The gender ratios of the samples from each country were compared with the na- 


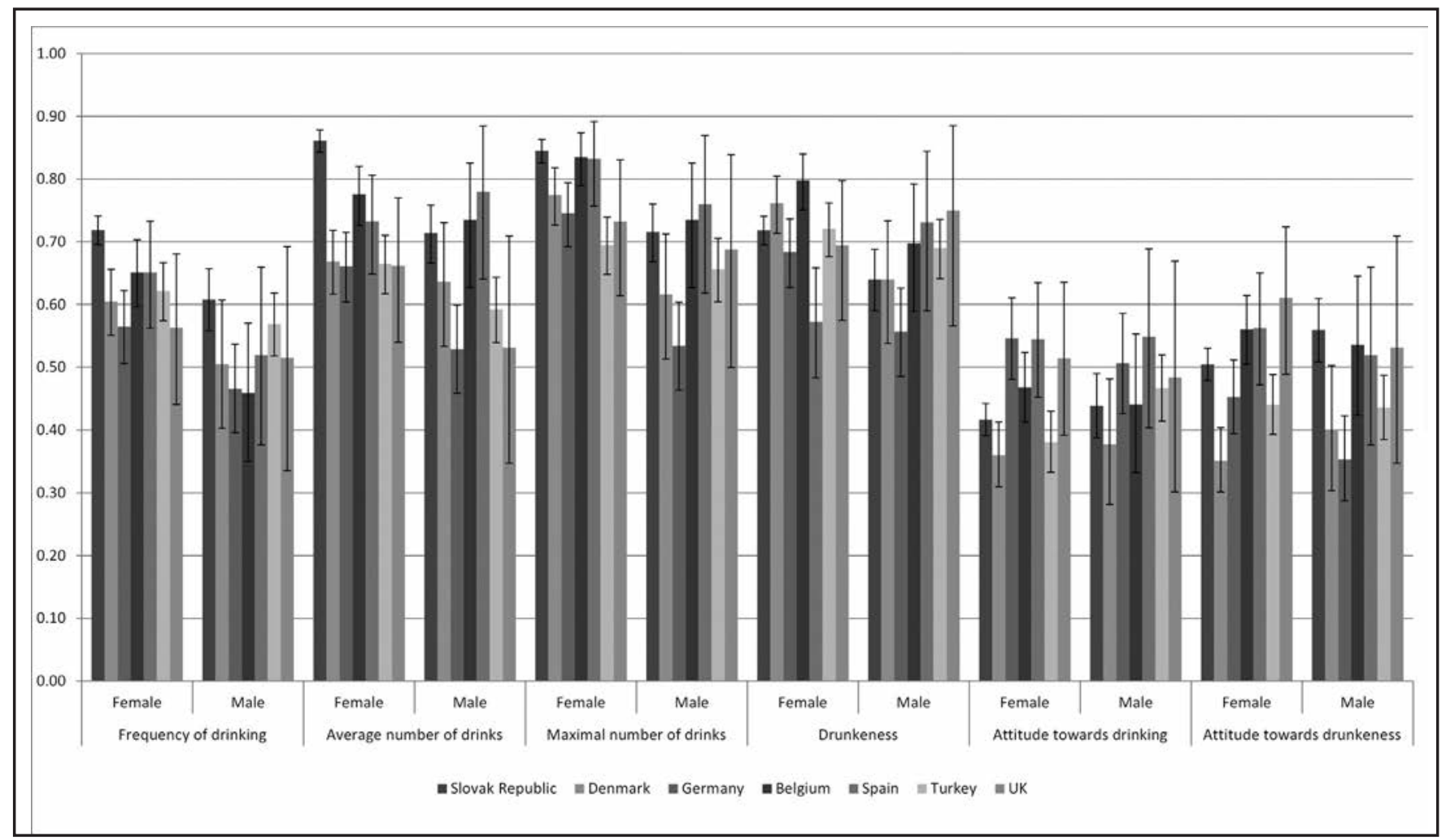

FIGURE 1. Fraction of respondents who ranked the behavior/attitudes of their peers as more risky or more permissible than their own behavior/attitudes by country and sex $(95 \%$ confidence intervals are displayed as error bars $)$. UK $=$ United Kingdom.

tional student population gender ratio for the year in which the survey was conducted, as taken from the Eurostat website (Eurostat, 2014). In Belgium, Denmark, Spain, the United Kingdom, and the Slovak Republic, between 69\% and 79\% of the sample were female, whereas the national percentage of female university students in these countries is between $50 \%$ and 59\%. The samples in Turkey and Germany were closer to the national gender ratios for university students, with a difference of approximately $8 \%$ more female students in the samples compared with the national population figures in each instance.

Figure 1 depicts the fraction of students who rated the behavior/attitudes of their peers as more risky/permissible than their own by country and sex. As such, any bar in excess of 0.5 (i.e., 50\%) indicates that the majority of respondents reported that they perceived the behavior or attitude of the majority of their peers at their institution to be more risky or permissive than their own attitude and behavior. Some general observations can be made. By trend, perceiving the behavior of others as more risky dominates the picture, but there is a substantial heterogeneity across countries and the studied variables. Also, effects of sex display heterogeneity. Considering others as having more risky behavior takes place particularly for the descriptive norms of the average or maximal number of drinks on one occasion and for drunken- ness. Typically, this was more the case for female than male students, particularly in Germany. For injunctive norms, the fraction of students rating the behavior of the majority as more risky than their own was lower than for descriptive norms. This was accompanied by a substantial fraction of those in agreement with the majority and just a marginal fraction of those who reported for themselves more permissive attitudes than for the majority of their peers. Sex differences were less evident with regard to injunctive norms than they were for descriptive norms.

The sensitivity analysis assessing variation within and between countries confirmed that most of the above-reported differences were attributable to country and not institution level. After we adjusted for sex and study term composition, variance at the institutional level was not significantly different from zero in most models (data not shown). The only exception was the attitude toward drinking alcohol. The fraction of those considering peers' attitude more permissive than their own attitude varied more within than between countries, as based on predicted probabilities for male students in their first year of study from a three-level binary logistic regression model adjusting for sex and year of study.

All studied risk behaviors were associated with the corresponding perceptions of peers' behavior. Those who perceived others to have more risky behavior were more likely 
TABLE 2. Association between perceived behavior of peers and own behavior ${ }^{a}$

\begin{tabular}{|c|c|c|c|c|c|c|}
\hline \multirow[b]{2}{*}{$\begin{array}{l}\text { Perceived behavior, } \\
\text { per unit }\end{array}$} & \multirow{2}{*}{$\begin{array}{c}\text { Frequency of } \\
\text { drinking } \\
\text { OR }[95 \% \mathrm{CI}]\end{array}$} & \multicolumn{2}{|c|}{ Typical no. of drinks } & \multirow{2}{*}{$\begin{array}{c}\text { Max. no. } \\
\text { of drinks } \\
\text { OR }[95 \% \mathrm{CI}]\end{array}$} & \multicolumn{2}{|c|}{ Drunkenness } \\
\hline & & $\begin{array}{c}\text { Male } \\
\text { OR }[95 \% \mathrm{CI}]\end{array}$ & $\begin{array}{c}\text { Female } \\
\text { OR }[95 \% \mathrm{CI}]\end{array}$ & & $\begin{array}{c}\text { Male } \\
\text { OR }[95 \% \mathrm{CI}]\end{array}$ & $\begin{array}{c}\text { Female } \\
\text { OR }[95 \% \mathrm{CI}]\end{array}$ \\
\hline Total sample ${ }^{c}$ & $1.21[1.16,1.26]$ & $1.36[1.31,1.41]$ & $1.31[1.24,1.38]$ & $1.15[1.13,1.17]$ & $1.26[1.15,1.39]$ & $1.30[1.19,1.42]$ \\
\hline Slovak Republic ${ }^{d}$ & $1.18[1.12,1.24]$ & $1.30[1.23,1.38]$ & $1.29[1.20,1.34]$ & $1.12[1.10,1.15]$ & $1.30[1.23,1.38]$ & $1.29[1.24,1.34]$ \\
\hline Denmark & $1.26[1.14,1.40]$ & $1.29[1.20,1.39]$ & $1.61[1.52,1.71]$ & $1.23[1.19,1.28]$ & $1.29[1.20,1.39]$ & $1.61[1.52,1.71]$ \\
\hline Germany & $1.32[1.21,1.45]$ & $1.47[1.35,1.61]$ & $1.55[1.45,1.66]$ & $1.25[1.20,1.30]$ & $1.47[1.35,1.61]$ & $1.55[1.45,1.66]$ \\
\hline Belgium & $1.33[1.21,1.45]$ & $1.22[1.12,1.33]$ & $1.39[1.30,1.48]$ & $1.16[1.12,1.20]$ & $1.22[1.12,1.33]$ & $1.39[1.30,1.48]$ \\
\hline Spain & $1.29[1.17,1.43]$ & $1.24[1.10,1.40]$ & $1.52[1.39,1.67]$ & $1.13[1.08,1.19]$ & $1.24[1.10,1.40]$ & $1.52[1.39,1.67]$ \\
\hline Turkey & $1.16[1.09,1.24]$ & $1.45[1.28,1.64]$ & $1.48[1.33,1.65]$ & $1.16[1.09,1.23]$ & $1.45[1.28,1.64]$ & $1.48[1.33,1.65]$ \\
\hline United Kingdom & $1.28[1.15,1.42]$ & $1.47[1.22,1.76]$ & $1.39[1.25,1.55]$ & $1.28[1.20,1.38]$ & $1.47[1.22,1.76]$ & $1.39[1.25,1.55]$ \\
\hline$p^{e}$ & .054 & .001 & $<.0001$ & $<.0001$ & .934 & .027 \\
\hline
\end{tabular}

Notes: $\mathrm{OR}=$ Odds ratio; $\mathrm{CI}=$ confidence interval; no. $=$ number; $\max .=$ maximum. ${ }^{a}$ Model is adjusted for age, sex, study year, residence type, and religiosity and includes country as random effect; when a significant two-way interaction between country, sex, and perceptions was detected, separate models for male and female students are reported; ${ }^{b}$ alcohol consumption once a week or more; ${ }^{c}$ model 1 without interaction effects between country and perceptions; ${ }^{d}$ model 2 with interaction between country and perceptions, effects of perception within each country are estimated from the joint model, stratified by sex in case of significant two-way interaction between country, sex, and perceptions; ${ }^{e}$ test for interaction between country and perceptions.

to report personal risky behaviors (Table 2). A similar result was found for the injunctive norms of attitudes, with those who perceived their peers to have more permissive attitudes toward alcohol use more likely to hold permissive attitudes themselves (Table 3). There was also some heterogeneity among the countries and differences in country effects by sex. The associations in the Slovak Republic and Turkey were typically among those that were weaker, whereas Germany, Denmark, and the United Kingdom were among those that were stronger. There was no indication of heterogeneity in country effects by sex for the studied attitudes, but the effects of perceived peers' typical number of drinks and drunkenness displayed significant variation. The effects of the perceived typical number of drinks of peers were particularly close in both sexes in the Slovak Republic and Turkey and showed the strongest differences in Denmark, Belgium, and Spain. For drunkenness, the effects of perceived peers' behavior did not vary by country among males, but there was significant heterogeneity among females. The effects were again similar in both sexes in the Slovak Republic and Turkey and substantially stronger in females than males in Denmark and Spain.

\section{Discussion}

The results of our study suggest that many students perceive that the majority of their same-sex peers use alcohol more frequently, have a higher number of drinks, and are drunk more often than they (the students themselves) are. This finding is consistent with findings of previous research into perceptions of peer alcohol use in younger, school-aged adolescents in Central and Eastern Europe (Page et al., 2008).

With respect to descriptive norms, it is of interest that the perception that others are behaving in a riskier way than oneself appears to be especially pronounced with regard to the typical number of alcoholic drinks, the maximum number of alcoholic drinks in a single session, and the frequency of drunkenness. It could be argued that these behaviors are the ones that are most closely aligned with heavy episodic drinking. In contrast to behaviors such as the frequency of alcohol consumption, they are also the behaviors that are most easily directly observed. It has been suggested that memory biases may be one of the causes of misperceptions of peer substance use (Perkins, 2003). Specifically, individuals are more likely to remember highly noticeable behavior in other individuals (such as drunkenness) and in turn to generalize that behavior to the wider group. Identifying which alcohol use behaviors may be most vulnerable to misperceptions is important for the development of more targeted and effective social norms interventions.

TABLE 3. Association between perceived attitudes of peers and own attitudes ${ }^{a, b}$

\begin{tabular}{lcc}
\hline $\begin{array}{l}\text { Perceived behavior, } \\
\text { per unit }\end{array}$ & $\begin{array}{c}\text { Attitudes toward } \\
\text { drinking }^{c} \\
\text { OR }[95 \% \mathrm{CI}]\end{array}$ & $\begin{array}{c}\text { Attitudes toward } \\
\text { drunkenness } \\
\text { OR }[95 \% \mathrm{CI}]\end{array}$ \\
\hline Total sample $^{d}$ & $2.02[1.80,2.27]$ & $1.83[1.60,2.09]$ \\
Slovak Republice $^{\text {Denmark }}$ & $1.98[1.60,2.44]$ & $1.78[1.43,2.20]$ \\
Germany & $2.99[2.15,4.16]$ & $2.55[1,82,3.57]$ \\
Belgium & $2.08[1.54,2.81]$ & $1.76[1.36,2.28]$ \\
Spain & $2.30[1.63,3.24]$ & $1.76[1.04,2,96]$ \\
Turkey & $2.49[1.53,4.06]$ & $1.86[1.22,2.84]$ \\
United Kingdom & $1.73[1.43,2.10]$ & $1.62[1.16,2.27]$ \\
& $2.17[1.35,3.50]$ & $1.52[1.01,2.28]$ \\
$p^{f}$ & & \\
\hline
\end{tabular}

Notes: $\mathrm{OR}=$ odds ratio; $\mathrm{CI}=$ confidence interval. ${ }^{a}$ Model is adjusted for age, sex, study year, residence type, and religiosity and includes country as random effect; ${ }^{b}$ in these analyses, no two-way interactions between country, sex, and perceptions were detected; ${ }^{c}$ alcohol use ok even if it does interfere with work or study; ${ }^{d}$ model 1 without interaction between country and perceptions; ${ }^{e}$ model 2 with interaction between country and perceptions, effects of perception within each country are estimated from the joint model; $f_{\text {test }}$ for interaction between country and perceptions. 
Similarly, it was observed in the current study that female students appeared to be more likely than male students to perceive the behaviors of other female students as riskier than their own behaviors. Research in the United States has demonstrated that female students tend to have larger misperceptions of same-sex peer alcohol use than do male students (Lewis \& Neighbors, 2004). This is relevant to the design of social norms interventions because genderspecific messages may be required for some behaviors and populations to maximize the impact of social norms campaigns.

The results for injunctive norms were more mixed, with students in some countries appearing to perceive their view of the acceptability of alcohol use and drunkenness to be similar to that of the majority of their peers. The use of differing survey items and response options makes direct comparisons of results for descriptive and injunctive norms difficult, but these results would appear to contrast with those of work in the United States, which indicate that students tend to perceive the majority of their peers to be more accepting of alcohol use than they themselves, in the same way as with respect to behaviors (Neighbors et al., 2008). This may be a reflection of wider differences in cultural norms toward alcohol use in Europe versus the United States. For example, it has been noted that, although alcohol use is a largely covert behavior on American college campuses, it is expected and accepted by British university authorities as an aspect of normal student behavior (Delk \& Meilman, 1996). Similarly, drinking on university premises is not banned in most European countries.

Nevertheless, the majority of students in each country held the view that alcohol use and drunkenness are unacceptable if they negatively affect work or studies. There was greater variation in the relationship between the students' own and peers' attitudes between sites within countries than there was between the countries overall. It was not clear why this was the case. It might be a random finding, given the number of analyses conducted, but there may also be some differences in the way students become aware of the attitudes of peers. Further qualitative research may help explore these questions.

Despite the mixed results of the current study, there remains a need to conduct more work on the role of injunctive norms and how these can be used to reduce alcohol use in students. It has been argued that changes to the perceived injunctive norm can result in longer term behavior changes than with the descriptive norm (LaBrie et al., 2010). This may reflect the different routes through which descriptive and injunctive norms have been proposed to operate. Descriptive norms may represent a decision-making heuristic (i.e., short cut) through which an individual can decide how to behave in a specific situation, such as how many alcoholic drinks to consume when in a bar with peers. Injunctive norms, on the other hand, may represent the values of the group to which the individual wants to belong and may be more stable over time and across different situations (Jacobson et al., 2011). Therefore, it may be more efficient for individuals to strive to adhere to the injunctive norm of the group rather than the descriptive norm.

In addition and as noted elsewhere, social norms feedback based on injunctive norms can be useful in situations where the actual descriptive norm is of a harmful level or not suitable for dissemination among the target population (Mollen et al., 2013). For instance, if the reported norm of the number of alcoholic drinks consumed on a night out or when partying is high, then an injunctive norms message that the majority of people will ensure that their friends do not travel home alone could be used as part of a harm-reduction campaign.

Perceived norms were also found to be significantly associated with personal alcohol use behaviors and attitudes for all of the corresponding outcome measures. This is consistent with previous research (Haug et al., 2011; Perkins, 2007). Regardless of whether these perceptions are indeed misperceptions, these results suggest that challenging perceived norms of alcohol use within a student population could result in a reduction of alcohol use. There were, however, some variations between countries on the strength of these associations by sex. This highlights the need to better understand how culture and sex interact with regard to social norms of alcohol use and how this can be addressed in the application of a cross-cultural social norms campaign.

There are a number of limitations to the study. These baseline data were collected using a cross-sectional survey. The analysis assumes that perceptions are the cause of behavior rather than behavior being the cause of perceptions. This assumption is supported by longitudinal studies in the field, although it has been noted that a degree of reciprocal causality is present (Neighbors et al., 2006). The students who have taken part in the study have been tracked from baseline to follow-up. Therefore, changes in behavior and perception will be examined from a longitudinal perspective when these follow-up data are analyzed. Limited resources dictated the inclusion of only two sites per country (an intervention and a control site) for the planned feasibility trial. Although more sites were included in some countries, neither were they representative of the countries nor did this occur in a systematic fashion. Therefore, the findings on variation within countries need to be considered with caution. The sample sizes from the United Kingdom and Spain were low compared with those of the other countries involved, although the results from the United Kingdom are consistent with previous studies (McAlaney \& McMahon, 2007). The overall sample included a higher proportion of female students than in the student populations of the participating institutions in all countries. Sex-specific perceived behavior and norms items were used in the survey, in which case sex imbalance is not of concern. 
A wider issue for the social norms field, which relates to the current study, is the use of the word misperception to discuss the discrepancy between the reported norm within a population and the perceived norm. To be confident that a perception is in fact a misperception in these cases, it would be necessary to demonstrate that the sample obtained is representative of the target population and that the data provided by respondents are accurate. Researchers in the field have provided evidence in support of the representativeness of samples in social norms research (Perkins et al., 2005) and the reliability and validity of self-reported alcohol use data (Del Boca \& Darkes, 2003; Lintonen et al., 2004); nevertheless, it could be argued that misperception is a word to be used with caution. An alternative approach, as done with regard to the results of this study, is to only identify whether self-other discrepancies exist, as in whether individuals think that their peers use more or less of a substance on average than they do themselves. If a majority of individuals think that the majority of their peers are engaging in a behavior more heavily than they themselves are, this could be taken as an indication that the perception is actually a misperception.

The results of this study suggest that self-other discrepancies around alcohol use of the type documented extensively in American college student populations are also evident in European student populations. In conjunction with previous research, the findings of this study also suggest that perceived peer norms are an important predictor of personal behavior and attitude. Returning to the aims of the analysis of the baseline data, the results of this study therefore suggest that a social norms approach may be a viable method of behavior and attitude change in European student populations. In light of the criticisms that have been made around traditional forms of alcohol harm prevention (Foxcroft et al., 2003), these results highlight the need to explore the social norms approach as a new avenue of behavior change in Europe.

\section{References}

Akmatov, M. K., Mikolajczyk, R. T., Meier, S., \& Krämer, A. (2011). Alcohol consumption among university students in North Rhine-Westphalia, Germany-Results from a multicenter cross-sectional study. Journal of American College Health, 59, 620-626.

Bendtsen, P., Johansson, K., \& Akerlind, I. (2006). Feasibility of an emailbased electronic screening and brief intervention (e-SBI) to college students in Sweden. Addictive Behaviors, 31, 777-787.

Bergen, H. A., Martin, G., Roeger, L., \& Allison, S. (2005). Perceived academic performance and alcohol, tobacco and marijuana use: Longitudinal relationships in young community adolescents. Addictive Behaviors, 30, 1563-1573.

Bewick, B. M., West, R. M., Barkham, M., Mulhern, B., Marlow, R., Traviss, G., \& Hill, A. J. (2013). The effectiveness of a Web-based personalized feedback and social norms alcohol intervention on United Kingdom university students: Randomized controlled trial. Journal of Medical Internet Research, 15(7), e137.

Boot, C. R., Dahlin, M., Lintonen, T., Stock, C., Van Hal, G., Rasmussen, S., \& McAlaney, J. (2012). A survey study on the associations between misperceptions on substance use by peers and health and academic outcomes in university students in North-West Europe. International Journal on Disability and Human Development, 11, 273-279.

Boot, C. R. L., Rosiers, J. F. M., Meijman, F. J., \& Van Hal, G. F. G. (2010). Consumption of tobacco, alcohol and recreational drugs in university students in Belgium and the Netherlands: The role of living situation. International Journal of Adolescent Medicine and Health, 22, 527-534.

Borsari, B., \& Carey, K. B. (2001). Peer influences on college drinking: A review of the research. Journal of Substance Abuse, 13, 391-424.

Borsari, B., \& Carey, K. B. (2003). Descriptive and injunctive norms in college drinking: A meta-analytic integration. Journal of Studies on Alcohol, 64, 331-341.

Del Boca, F. K., \& Darkes, J. (2003). The validity of self-reports of alcohol consumption: State of the science and challenges for research. Addiction, 98, Supplement 2, 1-12.

Delk, E. W., \& Meilman, P. W. (1996). Alcohol use among college students in Scotland compared with norms from the United States. Journal of American College Health, 44, 274-281.

Dowdall, G. W., \& Wechsler, H. (2002). Studying college alcohol use: Widening the lens, sharpening the focus. Journal of Studies on Alcohol, Supplement 14, 14-22.

European Monitoring Centre for Drugs and Drug Addiction. (2011). 2011 Annual report on the state of the drugs problem in Europe. Lisbon, Portugal: Author.

Eurostat. (2014). Tertiary education statistics. Retrieved from http://epp.eurostat.ec.europa.eu/statistics_explained/index.php/ Tertiary_education_statistics\#Database

Festinger, L. (1954). A theory of social comparison processes. Human Relations, 7, 117-140.

Foxcroft, D. R., Ireland, D., Lister-Sharp, D. J., Lowe, G., \& Breen, R. (2003). Longer-term primary prevention for alcohol misuse in young people: A systematic review. Addiction, 98, 397-411.

Ham, L. S., \& Hope, D. A. (2003). College students and problematic drinking: A review of the literature. Clinical Psychology Review, 23, 719-759.

Hartley, D. E., Elsabagh, S., \& File, S. E. (2004). Binge drinking and sex: Effects on mood and cognitive function in healthy young volunteers. Pharmacology, Biochemistry, and Behavior, 78, 611-619.

Haug, S., Ulbricht, S., Hanke, M., Meyer, C., \& John, U. (2011). Overestimation of drinking norms and its association with alcohol consumption in apprentices. Alcohol and Alcoholism, 46, 204-209.

Jacobson, R. P., Mortensen, C. R., \& Cialdini, R. B. (2011). Bodies obliged and unbound: Differentiated response tendencies for injunctive and descriptive social norms. Journal of Personality and Social Psychology, 100, 433-448.

Karam, E., Kypri, K., \& Salamoun, M. (2007). Alcohol use among college students: An international perspective. Current Opinion in Psychiatry, 20, 213-221.

LaBrie, J. W., Hummer, J. F., Neighbors, C., \& Larimer, M. E. (2010). Whose opinion matters? The relationship between injunctive norms and alcohol consequences in college students. Addictive Behaviors, $35,343-349$.

Lewis, M. A., \& Neighbors, C. (2004). Gender-specific misperceptions of college student drinking norms. Psychology of Addictive Behaviors, $18,334-339$.

Lintonen, T. P., \& Konu, A. I. (2004). The misperceived social norm of drunkenness among early adolescents in Finland. Health Education Research, 19, 64-70.

Lintonen, T., Ahlström, S., \& Metso, L. (2004). The reliability of selfreported drinking in adolescence. Alcohol and Alcoholism, 39, 362-368.

McAlaney, J., Bewick, B., \& Hughes, C. (2011). The international development of the 'Social Norms' approach to drug education and prevention. Drugs: Education, Prevention, \& Policy, 18, 81-89.

McAlaney, J., Boot, C. R., Dahlin, M., Lintonen, T., Stock, C., Rasmussen, 
S., \& Van Hal, G. (2012). A comparison of substance use behaviours and normative beliefs in North West European university and college students. International Journal on Disability and Human Development, 11, 281-287.

McAlaney, J., \& McMahon, J. (2007). Normative beliefs, misperceptions, and heavy episodic drinking in a British student sample. Journal of Studies on Alcohol and Drugs, 68, 385-392.

Mollen, S., Rimal, R. N., Ruiter, R. A. C., Jang, S. A., \& Kok, G. (2013). Intervening or interfering? The influence of injunctive and descriptive norms on intervention behaviours in alcohol consumption contexts. Psychology \& Health, 28, 561-578.

Monti, P. M., Miranda, R., Jr., Nixon, K., Sher, K. J., Swartzwelder, H. S., Tapert, S. F., . . C Crews, F. T. (2005). Adolescence: Booze, brains, and behavior. Alcoholism: Clinical and Experimental Research, 29, 207-220.

Moreira, M. T., Smith, L. A., \& Foxcroft, D. (2009). Social norms interventions to reduce alcohol misuse in university or college students. Cochrane Database of Systematic Reviews 2009, Issue 3. Art. No.: CD006748. DOI: 10.1002/14651858.CD006748.pub2.

Mota, N., Parada, M., Crego, A., Doallo, S., Caamaño-Isorna, F., Rodríguez Holguín, S., . . . Corral, M. (2013). Binge drinking trajectory and neuropsychological functioning among university students: A longitudinal study. Drug and Alcohol Dependence, 133, 108-114.

Neighbors, C., Dillard, A. J., Lewis, M. A., Bergstrom, R. L., \& Neil, T. A. (2006). Normative misperceptions and temporal precedence of perceived norms and drinking. Journal of Studies on Alcohol, 67, 290-299.

Neighbors, C., O’Connor, R. M., Lewis, M. A., Chawla, N., Lee, C. M., \& Fossos, N. (2008). The relative impact of injunctive norms on college student drinking: The role of reference group. Psychology of Addictive Behaviors, 22, 576-581.

O’Malley, P. M., \& Johnston, L. D. (2002). Epidemiology of alcohol and other drug use among American college students. Journal of Studies on Alcohol, Supplement 14, 23-39.

Page, R. M., Ihasz, F., Hantiu, I., Simonek, J., \& Klarova, R. (2008). So- cial normative perceptions of alcohol use and episodic heavy drinking among Central and Eastern European adolescents. Substance Use \& Misuse, 43, 361-373.

Perkins, H. W. (2003). The emergence and evolution of the social norms approach to substance abuse prevention. In H. W. Perkins (Ed.), The social norms approach to preventing school and college age substance abuse: A handbook for educators, counselors and clinicians (pp. 3-17). San Francisco, CA: Jossey-Bass.

Perkins, H. W. (2007). Misperceptions of peer drinking norms in Canada: Another look at the "reign of error" and its consequences among college students. Addictive Behaviors, 32, 2645-2656.

Perkins, H. W., Haines, M. P., \& Rice, R. (2005). Misperceiving the college drinking norm and related problems: A nationwide study of exposure to prevention information, perceived norms and student alcohol misuse. Journal of Studies on Alcohol, 66, 470-478.

Pischke, C. R., Zeeb, H., van Hal, G., Vriesacker, B., McAlaney, J., Bewick, B. M., ... Mikolajczyk, R. T. (2012). A feasibility trial to examine the social norms approach for the prevention and reduction of licit and illicit drug use in European University and college students. BMC Public Health, 12(1), 882.

Schulenberg, J. E., \& Maggs, J. L. (2002). A developmental perspective on alcohol use and heavy drinking during adolescence and the transition to young adulthood. Journal of Studies on Alcohol, Supplement 14, 54-70.

Stock, C., Mikolajczyk, R., Bloomfield, K., Maxwell, A. E., Ozcebe, H., Petkeviciene, J., . . . Krämer, A. (2009). Alcohol consumption and attitudes towards banning alcohol sales on campus among European university students. Public Health, 123, 122-129.

Weitzman, E. R., Chen, Y. Y., \& Subramanian, S. V. (2005). Youth smoking risk and community patterns of alcohol availability and control: A national multilevel study. Journal of Epidemiology and Community Health, 59, 1065-1071.

Wicki, M., Kuntsche, E., \& Gmel, G. (2010). Drinking at European universities? A review of students' alcohol use. Addictive Behaviors, 35, 913-924. 